\title{
Research on Improving the Inter-language Pragmatic Competence of University Undergraduates Based on Multimodality Theory
}

\author{
Hongyan Zheng, Tianjun Zhu* \\ ${ }^{1}$ Hebei University of Engineering, Department of Art, Handan 056038, China \\ ${ }^{2}$ Hebei University of Engineering, Department of Equipment Manufacturing, Handan 056038 , \\ China
}

695778960@qq.com;happy.adam2012@hotmail.com

\begin{abstract}
Keywords: ILP; multimodality; audio mode; visual mode
Abstract. The paper based on multimodality theory aims to improve the inter-language pragmatic competence of university undergraduates. Two subject classes are chosen, and then multiple modes of materials, tools and strategies are used in and out of classroom among the students of experimental class. The constant input in terms of visual modality, audio modality and kinesthetic modality bring about effective influence on the learners language awareness and improve the inter-language pragmatic competence of those subjects. The advantages and efficiency of multimodality-oriented teaching mode are verified in the post-experiment test which means the application of multi modes of teaching are very practical and useful in second language acquisition procedure.
\end{abstract}

\section{Introduction}

The purpose of the research tries to explore whether multimodal English teaching can be applied to improve students' inter-language pragmatic (ILP) competency. IL pragmatic competence plays a key role in understanding and performing of linguistic actions. Inter-language pragmatic theory emerged at the beginning of 1980s. In the primary stage, mainstream research of second language acquisition mainly concerned with three aspects of inter-language: normative speakers' comprehension, production and acquisition of second language pragmatic features. It's obvious that most of ILP studies concerned with second language application but not development [1].

In China, college students are an important part of English learners, and the developing of foreign language learners' IL pragmatic competence mainly depends on the classroom instruction. Therefore, in a foreign language learning setting, how to develop Chinese college students' ILP competence is quite necessary and worthwhile.

Multimodality is a term widely discussed by linguists and semioticians in recent years in the social semiotic fields in western countries. Linguists and semioticians often define it as follows: Van Leeuwen [2] defines multimodality as "the combination of different semiotic modes-for example, language and music-in a communicative artifact or event". Baldry [3] defines multimodality as "the diverse ways in which a number of distinct semiotic resource systems are both codeployed and co-contextualized in the making of a text-specific meaning".

Golfredi [4] states a new kind of literacy, i.e. the extensive use of multimodal literacy followed by the emergence of the internet. Caldwell [5] takes water circulation as example to show the collaboration between image and text in TESOL (Teaching English to Speakers of Other Language) class. Jewitt [6] combines multimodal semiotics with activity theory to discuss study from the perspective of multimodality. Kress [7] elaborates cross-language and cross-cultural multimodality based on systematic functional grammar and metaphor theory. O'Halloran [8] analyzes mathematical discourse from SF-MDA perspective, studies conceptual grammar and semiotic metaphor and explores multimodal construction in mathematical experience.

This paper takes multimodality, as a theory of teaching, employs various semiotic resources, such as visual, sound, pictures, gestures, color and others, to bring more senses into cooperative operation to study language, thus the best teaching effects will be achieved. 


\section{The Framework of the research Research Subjects}

The research was conducted within one academic year (from September2014 to July 2015) in Hebei Engineering University. The participants in the present research were two parallel Grade 2014 classes both majoring in Vehicle Engineering. According to students' university entrance examination grades and a pre-research test grades, students are classified into preparatory class, class A and class B. Class A was experimental class, in which multimodal English teaching method is used, while Class B was control class, in which traditional English teaching method is carried out.

\section{Research Material}

The textbook involved in the research is New Standard College English book I. It includes 10 units. Relevant PPT courseware used is created by foreign language teaching and research press. Every PPT Courseware employs multimodal symbols like pictures, words, video clips and sounds including tape recording and multimedia CD matched with textbooks. Meanwhile, the university and researchers provide environment for students' autonomous and interactive learning after class, so as to adapt diverse, networked and personalized English teaching needs, which is a teaching platform also provided by foreign language teaching and research press.

\section{Research Framework}

The research procedures included three stages: pre-experiment, experiment and post-experiment. Tests were given in both pre-experiment and post-experiment to evaluate students' proficiency in English skills. This paper aim to create a three-dimension interaction learning environment with multimodality application--- interaction of multi factors in class, interaction of studying time in and out of English class, interaction of students' major knowledge and English knowledge.

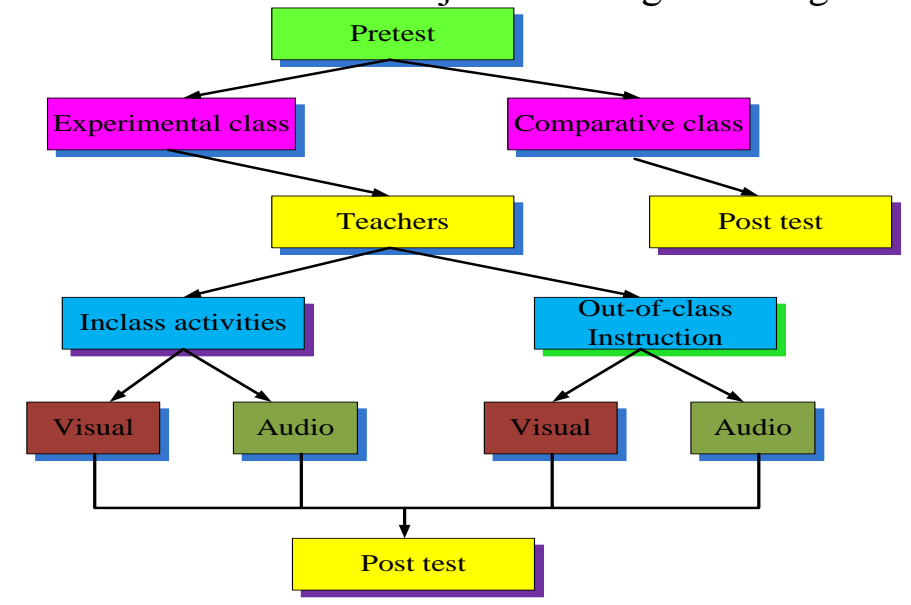

Figure 1 The Framework of the Research

During the experiment, an example about how multimodal English teaching methods applied in class was introduced. In order to test whether multimodal English teaching is better than traditional English teaching methods, the research chooses an experimental class as well as a comparative class. Various factors must be taken into account before the research is done, avoiding errors so as to contrast effects. In this part, a research is designed and procedures are given.

The two classes had the same teacher but with different teaching methods. In Class A, multimodal teaching method was used. Through multimodal teaching, students could notice and perceive various kinds of modalities, such as sound, pictures, words and videos etc. All of them could stimulate students' senses to actively participate in the class activities. On the contrary, in Class B the teacher made use of traditional teaching methods in ordinary classrooms and spent most of time analyzing language points, explaining grammar and translating the texts. The students grasped English only through practices.

\section{The Development of Multimodality Application In And Out Of English Class}

This research emphasizes the importance of viewing in language learning, the effect of viewing is decided by whether image participants and viewer are close or distant. The degree of the relationship between participants and viewer depends on distance of shot. Kress and van Leeuwen [9] mainly distinguish three types of social distance: close up, medium shot and long shot. 


\section{Multi factors in class}

It is usually not convenience for Chinese learners to contact with an authentic English language context in classroom environment. Textbooks are the major media for students to learn a foreign language. While in this research, other factors are also important in improving their ILP competency. Authentic teaching materials provide college students with living examples of real communication in a certain context and enable students to know how to behave appropriately the details and they should notice.

Not only the language and the intonation used by the teacher play an important role in the class, but also the mood, the gestures, even the way of dressing can be essential to keep learners awake and keen. The teacher use clear and formal voice to begin the class. This kind of audio and visual communication is helpful to reduce the distance between the teacher and the students. And the teacher's facial expressions and gestures serve as another important aspect of teacher's multimodality. Studying time in and out of English class

External factor is one of the main factors affecting the second language acquisition. The external factor includes social context and input which influence the probability of exposing to the authentic native language. Therefore it is very important to provide out of class activities for the language learners.

Various out of class programs are provided during the whole period. For example, the campus broadcasting station plays different recordings every day such as VOA special English, short stories, and popular songs. This constant audio modality exposure surly creates an English speaking background. In addition, some homework includes surfing the internet to find some specific information or to finish online exercise on the online autonomous learning system in which audio and visual modality alternate appears. It is an effective method to solve problems and the best way for information technology applied in teaching.

\section{Data Analysis}

Corrective feedback is any provision of information to students upon erroneous utterances, indicating the incorrect use of the TL and as well, encouraging students' rectification involving accuracy and precision. It can be seen that in pragmatic instruction, corrective feedback is a useful follow-up activity to focus learners' attention again on the pragmatic rules and reinforce learners' pragmatic awareness. See the details in the following table:

Table1 : Structure of Tests

\begin{tabular}{|l|c|l|}
\hline Item Type & Number of Items & Score Distribution \\
\hline Listening Comprehension & 30 & 30 \\
\hline Reading Comprehension & 30 & 40 \\
\hline Translation & 1 & 15 \\
\hline Writing & 1 & 15 \\
\hline
\end{tabular}

Table 2: The Average Score in the Pretest

\begin{tabular}{|l|l|l|}
\hline Category & Number & Average score \\
\hline Experimental class & 30 & 60.6 \\
\hline Comparative class & 30 & 60.5 \\
\hline
\end{tabular}

As mentioned above, the longitudinal research was carried out to Group A. The teacher adopted the explicit instruction together with implicit instruction. While after a year of separate teaching, the experimental class students have a much better performance than comparative class, respectively $2.9 \%$ higher in listening, 2.2\% higher in translation, $4.9 \%$ higher in reading and $1.8 \%$ higher in writing. The details are shown in table 3:

Table 3:The students performance in the post test

\begin{tabular}{|l|l|l|l|l|}
\hline Test type & Listen -ing30\% & Translation15\% & Reading40\% & Writting15\% \\
\hline Experimental class & 23.3 & 13.8 & 33.5 & 13.2 \\
\hline Comparative class & 20.4 & 11.6 & 28.6 & 11.4 \\
\hline
\end{tabular}

Generally speaking the total score of experimental class are $11.8 \%$ higher than the comparative class which shows the efficiency of multimodality application. This finding can also serve as a proof to the hypothesis-college students' IL pragmatic competence can be improved by classroom 
instruction and outside classroom activities. It shows us non-English majors could improve their ILP competency by constant contact with English and the culture in their learning process.

Table 4: The average score in the post test

\begin{tabular}{|l|l|l|}
\hline Category & Number & Average score \\
\hline Experimental class & 30 & 83.8 \\
\hline Comparative class & 30 & 72.0 \\
\hline
\end{tabular}

Through analyzing scores of pre-test and post-test and questionnaire as well, it is observed that application of multimodality has a profound effect on English learning. Modalities of pictures, gestures, sounds and actions have a vivid characteristic, which can better help students understand their communicating meaning they express. Integration of image-text resources can cultivate students' English skills. Visual grammar taking advantage of pictures and other different modality can lower materials' difficulty and consolidate learning effects.

\section{Conclusion}

First, modal conversion can strengthen and increase the durability of the contents of memory. This study found that memory is related with modality obtaining information. Among various sensory organs, the relationship between smell and memory is acknowledged.

In English classes, teachers' use of multimodality can create a relaxed learning environment for students, thus it can motivate students' learning interest and give play to students' personality. Meanwhile, multiple modes affect students' sense, so relevant knowledge can be aroused in students' brains. Multimodality can make students grasp key and correct information, and improve their accuracy of questions.

\section{Acknowledgment}

The authors would like to acknowledge the financial support of Hebei Provincial Social Science (HB15YY056), Research and Practice on the reform of Higher Education in Hebei Province (2015GJJG100) and Major project of Hebei University of Engineering.

\section{References}

[1] Kasper G K, R Rose. Pragmatics and SLA [J]. Annual Review of Applied Linguistic, 1999,(19):81-104.

[2] van Leeuwen, T. Introducing social semiotics [M]. London: Routledge, 2005.

[3] Baldry, A. \& P. Thibault. Multimodal transcription and text analysis: a multimedia toolkit and coursebook [M]. London: Equinox, 2006.

[4] Golfredi, A. Information retrieval and language education [A]. In A. P. Baldry (ed.). Multimodality and multimediality in the distance learning age [C]. Campobasso, Italy: Palladino Editore, 2000.

[5]Caldwell, D. Making many meanings in popular rap music [A]. In A. Mahboob \& N. K Knight (eds.). Appliable linguistics [C]. London \& New York:Continuum, 2010.

[6]Jewitt, C. Technology, literacy and learning: a multimodal approach [M].London\& New York: Routledge, 2006.

[7]Kress, G. and van Leeuwen, T. Multimodal discourse: the modes and media of ontemporary communication [M]. London: Armold, 2001.

[8]O’Halloran, K. L. Multimodal discourse analysis: systemic-functional perspectives [M]. London: Continuum, 2004..

[9]Kress, G. and van Leeuwen, T. Reading images: the grammar of visual design (2nd ed.) [M]. London: Routledge, 2006. 